\title{
Research on Emergency Coordinated Control System of Reactive Power and Voltage in Shandong Power Grid
}

\author{
Ruhu Dai ${ }^{1,2, a}$, Xuedong $\mathrm{He}^{1,2, \mathrm{~b}}, \mathrm{Ke} \mathrm{Xu}^{1,2, \mathrm{c}}$, Gengxin Cao ${ }^{1,2, \mathrm{~d}}$ and Kai Wang ${ }^{1,2, \mathrm{e}}$ \\ ${ }^{I}$ NARI Group Corporation, Nanjing, Jiangsu, China \\ ${ }^{2}$ NR Electric Co.,Ltd., Nanjing, Jiangsu, China \\ adairh@nrec.com, ${ }^{b}$ hexd@nrec.com, ${ }^{c} x u k e @ n r e c . c o m,{ }^{d}$ caogx@nrec.com, ${ }^{e}$ wangk@nrec.com
}

\begin{abstract}
This research project uses the existing capacitors, reactors and other reactive power resources in substations to construct the first regional reactive power and voltage emergency coordinated control system to solve the voltage problems after DC commutation failure or blocking. The system adopts the centralized control structure of master station, sub-station and executive station. The coordinated control master station communicates with AVC master station and converter substation sub-station to determine the fault, and then sends action instructions through the optical fiber communication to reasonably switch the capacitors and reactors of relevant substation, so as to give fast and effective reactive dynamic compensation to key nodes of the power grid to avoid voltage collapse.
\end{abstract}

Keywords: reactive power and voltage, emergency coordinated control, voltage stability, voltage collapse, multi-infeed DC

\section{INTRODUCTION}

With the gradual operation of large-capacity UHVDC, the characteristics of "strong DC and weak $\mathrm{AC}$ " are becoming increasingly prominent in the initial stage of UHV power grid construction, and the interaction between $\mathrm{AC}$ and $\mathrm{DC}$ is aggravated. Especially, the AC fault of multi-infeed power grid may lead to the simultaneous commutation failure of multiple DC lines, which will cause huge short-term power impact on the sending-receiving-end system and cause large power fluctuation of UHV tie-line. And it threatens the safe and stable operation of UHV AC/DC hybrid power grid. After many DC feeds into Shandong Province, such as Lugu, Zhaoyi and Yindong, the risk of voltage stability damage in Shandong power grid, especially in the eastern region, has increased dramatically. It is urgent to take various control measures to improve the voltage stability of the power grid. In order to improve the voltage stability of the power grid, priority should be given to the use of the existing reactive power control resources, and to play its role through emergency coordination control. At present, the reactive power control resources of power grid include:

- At the peak load of power grid, there are still a large number of capacitors in standby state. Through fast switching capacitors and reactors, it can play a role in voltage emergency control, and has better technical and economic advantages.

- High voltage capacitors and filters installed in HVDC converter substation, as well as large capacity phase modulators. The original purpose of these devices is to ensure the safe and stable operation of the HVDC transmission system. Through coordinated control and other technical means, they can also play a role in the voltage stability of the whole power grid.

- Considering that the new energy power electronic converter also has the ability of reactive power and voltage control, it can also be used as a resource of reactive power and voltage control.

\section{ANALYSIS OF VOLTAGE STABILITY IN SHANDONG POWER GRID}

\subsection{Summary Reasons of Voltage Stability Problems}

Three-circuit DC feeds into Shandong and new energy output proportion increases. Due to unit replacement effect, the start-up of thermal power units in Shandong power grid decreases, the short-circuit capacity of power grid is small, and the voltage support force is weak. In the case of large disturbance, the dynamic reactive power support can be provided by the strong excitation of conventional power supply, while the DC will absorb reactive power from the system for a short time, which seriously affects the transient voltage stability of the system. Calculated results show that under bad conditions, $1000 \mathrm{kV}$ Hequan double-line or Quanle double-line N-2 fault will lead to voltage collapse of Shandong power grid. The fundamental reason is that the power grid voltage support is weak and can not withstand the low voltage caused by the big fault, which will lead to the blockage of DC after the failure of continuous commutation, and eventually lead to the voltage collapse of Shandong power grid.

Low voltage capacitors and reactors of each substation have an important impact on nearby voltage. At present, most of them are controlled by AVC or switched manually by dispatchers or operators, which can only achieve slow regulation of near-zone voltage for a long time, and can not meet the urgent reactive power demand under short-term serious fault. 


\section{EMERGENCY CONTROL SYSTEM POWER AND VOLTAGE \\ COORDINATED \\ OF REACTIVE}

\section{Problems}

To solve the voltage stability problem of Shandong power grid, conventional solutions include mode pre-control, adding dynamic reactive power compensation equipment, etc., but both of them have some drawbacks.

\subsubsection{Mode Pre-controlbstract}

If the grid structure and component parameters are not changed, in order to avoid the risk of voltage stability under specific faults, it is necessary to pre-control the operation mode of Shandong power grid, including pre-control of important section power flow, start-up mode and DC power.

There are many drawbacks in the way of pre-control:

- The transmission capacity of UHV AC/DC transmission lines cannot be fully utilized.

-It is impossible to make full use of the power flow transmission capacity of each section.

- The ability to solve voltage recovery problems caused by large-scale power flow transfer is limited.

-It is not conducive to the absorption of new energy.

Mode pre-control is to ensure the stability of power grid by sacrificing the economy of power grid under the condition of unchanged existing resources. Mode pre-control can only be an expedient measure without better measures, and can not be used as a final solution to the problem.

\subsubsection{Adding Dynamic Reactive Power Compensation Equipment}

Adding reactive power compensation equipment, such as phase modulator and FACTS equipment, is also a routine solution to the problem of voltage stability, which also has some drawbacks.

- Single-point equipment is difficult to solve large-scale voltage stability problems. Voltage stability of Shandong power grid is global and holistic, which needs to be improved as a whole or distributed dynamic reactive power compensation measures.

- Low cost performance. The investment of phase modulator and FACTS equipment is very large, which only plays a role after the power grid failure, and the investment return is relatively low.

-Voltage stability risk has the characteristics of local occurrence and rapid spread. If the low voltage has spread rapidly, the phase modulator and FACTS equipment of individual substations will not be able to solve the large area of low voltage problem.

\subsection{Brief introduction of Emergency Coordinated Control System of Reactive Power and Voltage}

In this project, a new set of reactive power and voltage emergency control device is added to the converter substations and some $500 \mathrm{kV}$ and $220 \mathrm{kV}$ substations. Optical fiber communication is used between the substations to form a set of reactive power and voltage emergency coordinated control system. When the device of the converter substation judges that DC commutation fails or is blocked, it sends the instruction of switching low-voltage capacitor and reactor to the subordinate substations to achieve voltage stability.

From the point of view of a substation, it is no different from the switching of conventional capacitors and reactors, but as a whole, the reactive power and voltage emergency control system can be used as a distributed, quasi-continuous dynamic reactive power compensation equipment. According to the fault information and real-time voltage, the capacitors and reactors can be switched dynamically to realize reactive power dynamic compensation.

The scheme has three outstanding advantages:

-Distributed solution.

- Fast control.

-Small investment and quick effect.

\subsection{Research on Site Selection and Determining Capacity of Emergency Coordinated Control System of Reactive Power and Voltage}

Based on the principle of site selection and determining capacity, this paper analyses the steady-state voltage and transient voltage separately, chooses economical and effective layout substations, and puts forward feasible site selection and determining capacity schemes, so as to give full play to the role of reactive power and voltage emergency coordinated control system.

\subsubsection{Site Selection and Determining Capacity Principle}

The principles of site selection and determining capacity are as follows:

a) Have enough control quantity: Considering the control effect and the margin of normal operation, the reactive power and voltage emergency coordinated control system needs to be equipped with sufficient controllable quantity.

b) Acting directly on the lesion: The voltage weak points in the steady-state and transient process are selected. Voltage stability has the characteristics of local collapse and rapid spread. Quick reactive power support at the lowest voltage substations can greatly improve the voltage stability of the whole power grid. 
c) Do not choose the substation which is directly connected to the power plant or adjacent to the power plant: The reactive power support in the near area of power plant is relatively sufficient. Considering the economy of investment and the effect of switching capacitor and reactor, it is not necessary to configure substations in the near area of power plant.

d) No plant or substation far from the converter substation is selected: The causes of voltage problems in Shandong power grid are complex, which are related to the start-up capacity of the whole power grid, the failure of DC commutation, the large-scale power flow transfer, load characteristics and the characteristics of reactive power compensation equipment, but the main reasons are still caused by DC converter substation. In order to solve this voltage stability problem, it is necessary to provide a large number of reactive power support to DC converter substation urgently after faults, and the reactive power support capacity of power substations with long electrical distance is limited. Therefore, reactive power and voltage emergency coordinated control system needs to be installed at substations near the converter substation.

e) Configure the switchable capacitors and reactors at the selected station: These stations included in the reactive

Table 1 The influence of switching capacitor (1p.u.) on the voltage of converter station in $220 \mathrm{kV}$ substation(1p.u.=100MVA)

\begin{tabular}{cccc}
\hline Converter substation voltage & $\begin{array}{c}\text { Yinan converter } \\
\text { substation }\end{array}$ & $\begin{array}{c}\text { Guanggu converter } \\
\text { substation }\end{array}$ & $\begin{array}{c}\text { Jiaodong converter } \\
\text { substation }\end{array}$ \\
\hline Yishui substation & 1.09 & 0.3 & 0.49 \\
Sunzu substation & 1.11 & 0.31 & 0.49 \\
Yangdu substation & 1.05 & 0.3 & 0.47 \\
Zhengjia substation & 0.34 & 1.2 & 0.53 \\
Qingzhou substation & 0.35 & 1.25 & 0.55 \\
Huanglou substation & 0.34 & 1.15 & 0.52 \\
Shangcheng substation & 0.43 & 0.44 & 1.12 \\
Jiaozhou substation & 0.42 & 0.42 & 1.09 \\
Gaomi substation & 0.46 & 0.46 & 1.24 \\
\hline
\end{tabular}

\subsubsection{Transient Voltage Analysis}

According to the voltage curve of Shandong $220 \mathrm{kV} \mathrm{AC}$ busbar when Qanle double-line N-2 fault occurs, the voltage level of substations such as Luandong Station, Luanqiu Station and Lubayi Station is relatively lower and the recovery speed is slower after the fault. These substations are all near the landing points of Lugu DC and Zhaoyi DC. The voltage level of areas near Guanggu and Linyi converter substations is low. Therefore, the low-voltage capacitors and reactors near DC landing sites should be selected first.

\subsubsection{Site Selection and Determining Capacity Scheme}

Based on the analysis of steady-state and transient voltage, combined with the calculation of a large number of application effects, and considering a certain margin, the site selection scheme of Shandong reactive power and voltage emergency coordinated control project is: $220 \mathrm{kV}$ substations in Qingdao, Linyi and Weifang three areas and power and voltage emergency coordinated control system should have switchable capacitors and reactors with appropriate capacity, and be convenient for implementation of the project.

\subsubsection{Steady Voltage Analysis}

The influence of short circuit current and switching capacitor on the voltage of converter substation:

a) Short circuit current: Through the analysis of shortcircuit current of converter substation, the short-circuit capacity of Yindong DC Jiaodong converter is larger, the dynamic reactive power support is more sufficient, and the near-zone voltage level is higher. However, the short-circuit capacity of Lugu DC Guanggu converter and Zhaoyi DC Yinan converter is smaller, the dynamic reactive power support is weak, and the near-zone voltage level is lower. Emphasis should be placed on the control of capacitors and reactors in the near area of Guanggu and Yinan.

b) Switching capacitor: The influence of switching capacitor (1p.u.) on the voltage of converter station in 220 $\mathrm{kV}$ substation is shown in the table below.

$500 \mathrm{kV}$ substations in the vicinity. The simulation results show that switching capacitors and reactors can effectively solve the problem of voltage instability.

The capacity of the selected substations capacitors and reactors is as follows:

- The total capacity of $500 \mathrm{kV}$ reactor is $2100 \mathrm{MVar}$, the total capacity of capacitor is 2940 MVar, and the total capacity of capacitor and reactor can be switched on and off under typical power flow is 2520 MVar.

- The total capacity of $220 \mathrm{kV}$ capacitor is $1400 \mathrm{MVar}$, and the total capacity of capacitor can be switched on under typical power flow is 1190 MVar.

\subsection{Scheme of Reactive Power and Voltage Emergency Coordinated Control System}

\subsubsection{Architecture of Reactive Power and Voltage Emergency Coordinated Control System}

Combined with the mature design of existing control devices, Shandong reactive power and voltage emergency 
coordinated control system adopts the centralized control structure of master station, sub-station and executive station, and uses $2 \mathrm{M}$ communication channel to communicate directly between stations. Under normal control mode, the coordinated control sub-station sends the collected capacitor and reactor information to the master station. The coordinated control master station takes measures to switch on or off the capacitor and reactor in this area according to the fault situation and voltage.

The structure of reactive power and voltage emergency coordinated control system is shown in Figure 1.

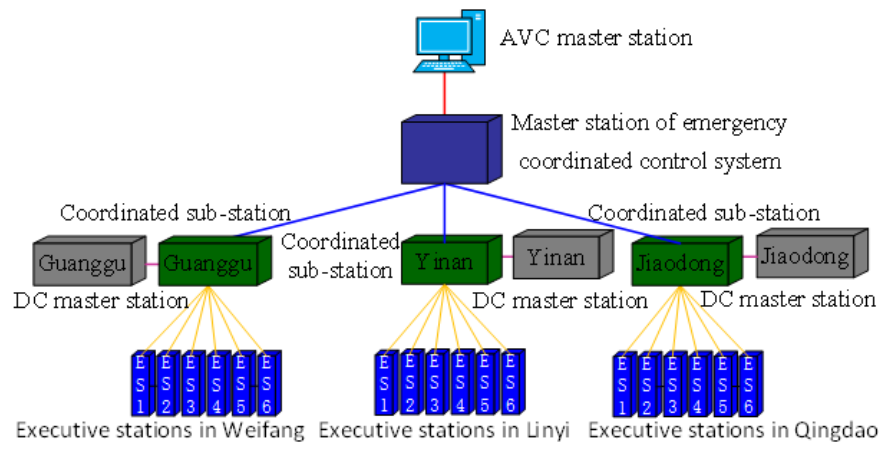

Figure 1 The structure of reactive power and voltage emergency coordinated control system

The functions of main equipment of the system are as follows:

a) Specific functions of coordinated control master station:

- Receiving system operation mode of AVC master station and reactive power control capacity under various kinds of faults.

- Receiving DC operation and fault information of coordinated control sub-stations of Yinan, Guanggu and Jiaodong, and sending reactive power modulation capacity command to each sub-station according to the scheduled control strategy.

b) Specific functions of coordinated control sub-station:

- Sending DC operation and fault information to coordinated control master station, and receiving and executing command of reactive power modulation capacity of coordinated control master station.

- Receiving DC operation and fault information of DC master station of converter substation.

- Receiving operation information of capacitors and reactors in each executive station, and sending switching capacitors and reactor commands to each executive station when faults occur.

-When the busbar overvoltage or low voltage of converter substation reaches the operating value, the capacitor and reactor of the substation are switched on or off according to the predetermined scheme.

c) Specific functions of executive station:

- Sending the operation status information of capacitors and reactors to the superior control station, and receiving and executing switching capacitor and reactor commands of the superior control station.

-When the busbar overvoltage or low voltage reaches the operating value, the capacitor and reactor of the substation are switched on or off according to the predetermined scheme.

\subsubsection{Incorrect Switching Prevention Measures for Emergency Coordinated Control of Reactive Power and Voltage}

The emergency coordinated control system of reactive power and voltage must take the following preventive measures.

a) Preventing mis-switching capacitors and reactors:

- Judging whether the reactor can be switched on or off according to the operation status of the main transformer connected to it.

- Judging whether the capacitor can be switched on or off according to the operation status of the main transformer connected to it. Within the time $\mathrm{t} 1$ after the capacitor exits, no input is allowed, and the $\mathrm{t} 1$ value can be set.

- Capacitors are not allowed to be put in before the reactor exits, and reactors are not allowed to be put in before the capacitor exits.

b) Preventing misoperation in overvoltage:

- Capacitor and reactor switching must be combined with the voltage level of the substation. When the voltage is above the upper limit, the capacitor is not allowed to be input, and when the voltage is below the lower limit, the reactor is not allowed to be input.

-When the voltage of the substation is above the upper limit, removes the capacitor or inputs the reactor of the substation after $\mathrm{T} 2$ seconds of delay, and the $\mathrm{t} 2$ value can be set.

\subsubsection{Strategy of Emergency Coordinated Control System for Reactive Power and Voltage}

a) Control strategy for switching off reactor and switching on capacitor of master station

Before the accident, the master station receives the information of switchable capacitor and reactor, the short circuit capacity information of relevant substations sent by AVC master station, and the calculation results of online switching amount. The master station switching strategy is based on DC commutation failure or blocking signal, and starts switching combined with local voltage. According to the collected voltage of the converter substation before the accident and the set value of the voltage control target, the reactive power demand of the three converter substations is calculated, the input amount of the reactive resources of each substation is accurately allocated, and the local low voltage 
Control in Power Systems", Control and Decision, Vol.20(12), pp.1337-1341, 2005. after the fault is effectively managed by adopting the onetime switching capacitor and the reactor measures.

There are three schemes for calculating the switching capacity of the master station:

- The switching capacity of the capacitor is roughly calculated according to the short-circuit capacity without regard to the influence between substations.

- The real-time information is collected to judge the fault, and the dynamic switching is carried out according to the fault type.

-According to the integral of voltage drop of converter substation, the switching is performed in stages according to the time.

b) Reactive power resource exit strategy based on realtime voltage

(1) Overvoltage Control Strategy of Master Station

After reactive power dynamic support, if the system voltage is high and there is no DC commutation failure or blocking signal, start capacitor exit or reactor input. When the voltage of all control stations is lower than the highvoltage fixed value, the switching is blocked.

(2) Overvoltage Control Strategy of Sub-station

-When the sub-station overvoltage, switch off capacitor or switch on reactor with delay.voltage value is set with several rounds.

- Switch off capacitor or switch on reactor according to overvoltage integral.

c) Executive station voltage switching strategy

Executive station receives control commands from master station or sub-station, and performs switching operation combined with local voltage.

\section{CONCLUSION}

Closely combined with the actual development of China's power grid and based on the existing capacitor and reactor switching applications, this project constructs the reactive power and voltage emergency coordinated control system of Shandong power grid, gives the problem analysis, system scheme, control strategy and so on. The results show that the reactive power and voltage emergency coordinated control system can provide emergency support for the voltage during the fault period of the power grid, significantly enhance the voltage stability, ensure the safe operation of the power grid, and thus generate huge social and economic benefits.

\section{REFERENCES}

[1] Wang Ke, Yang Shengchun, and Yao Jianguo, "Emergency DC Power Support with Reactive Power Coordinated Control for Multi-circuit HVDC Systems", Automation of Electric Power Systems,vol. 35(18),pp.103107, 2011.

[2] Long Jinzhuang, Han Minxiao, and Guo Xiaojiang, "Strategy of Emergency Power Support and Voltage Stability Control with HVDCs", Modern Electric Power, vol. 27(1), pp.30-34, 2010.

[3] Sheng Gehao, Jiang Xiuchen, and Fan Xihui, "Optimal Coordination for Multi-agent Based Secondary Voltage 